\title{
Remote Sensing of Temporal and Spatial Variations of Suspended Sediment Concentration in Bahmanshir Estuary, Iran
}

\author{
Mohammad Bagher Kazemzadeh, Seyed Ali Ayyoubzadeh* and Ali Moridnezhad \\ Department of Water Structures Engineering, Tarbiat Modares University, Tehran, Iran; \\ mb.kazemzadeh@modares.ac.ir; ayyoub@modares.ac.ir; moridnezhad@gmail.com
}

\begin{abstract}
Suspended Sediment Concentration (SSC) in surface waters affects directly on the water quality, phytoplankton's fertility, pollution distribution and redistribution. In this study, temporal and spatial variations of SSC at Bahmnshir Estuary (BE) in the southwest of Iran were investigated using five field campaigns and Moderate Resolution Imaging Spectroradiometer (MODIS) sensor images of a nine-year time series from 2003 to 2011. An Artificial Neural Network (ANN) model with one hidden layer that had good simulation performance (training: $\mathrm{R}^{2}=0.84 ; \mathrm{N}=23$; validation: $\mathrm{RMSE}$ of $59 \mathrm{mg} \mathrm{L}^{-1}, \mathrm{~N}=6$ ) was used against regression analysis (modeling: $\mathrm{R}^{2}=0.63 ; \mathrm{N}=23$; validation: RMSE of $261 \mathrm{mg} \mathrm{L}^{-1}, \mathrm{~N}=6$ ). Results indicated ANN model has higher accuracy than regression analysis to model the SSC because it's higher capability in optimization of non-linear problems. $\mathrm{R}^{2}$ and RMSE were improved, 25 and $77 \%$ respectively when using ANN model. It was found that average annual SSC for years 2008 to 2011 was $10 \%$ more than years 2003 to 2007 and the highest SSC accrued at 2008 with a noticeable decrease in the flow discharge of Karun River in this year. Minimum SSC occurs, at the point in $3.2 \mathrm{~km}$ before the Estuary Mouth (EM). This point was defined as the boundary of impact of upstream and downstream on the SSC in the BE. High SSCs occur at EM, at the muddy shore of the Abadan Island on right bank and at the Khoure Mousa on the left bank with 2.8 and $1.8 \mathrm{~km}$ distance from the EM respectively. This study demonstrated ANN model and MODIS MOD09GQ products are appropriate tools for monitoring surface SSC dynamics within coastal water environments such as BE.
\end{abstract}

Keywords: Bahmanshir Tidal River Estuary, MODIS, Remote Sensing, Suspended Sediment Concentration, Temporal and Spatial Variation.

\section{Introduction}

Estuaries are productive regions and diverse coastal areas that are also critical to commerce, transportation and recreation activities [17]. Estuaries usually are located close to cities or to commercial agricultural activities, and are the downstream recipients of sediments, nutrients, and other discharges generated from inland sources such as Bahmanshir Estuary (BE). The BE in the southwest of Iran has a free connection to the Persian Gulf and is the most important water resource for Abadan and Khorramshahr cities that have 217,988 and 123,866 population respectively according to the 2006 census [48, 32]. Therefore, obtaining water quality of $\mathrm{BE}$ is necessary to provide a basis for more informed coastal management decisions.

Suspended Sediment Concentration (SSC) is an important indicator in monitoring environmental changes in the marines and especially in coastal areas [38, 35, 26]. Patterns of SSC distribution affect pollutant movement [30] and nutrient dynamics [24]. The distribution of suspended

${ }^{*}$ Corresponding author:

Seyed Ali Ayyoubzadeh (ayyoub@modares.ac.ir) 
sediment varies in different coastal areas and over a broad spectrum of space and time scales [15]. The traditional field methods for measurement of SSC have limitations over large areas [14], and are constrained by severely limited temporal and spatial samplings due to the time-consuming, high cost, and the need for laboratory analysis need [31], which can be overcome by using remote sensing [8, $45,5,29]$. The remote sensing is a useful technique, which has been developed rapidly over the last years, to study the SSC in estuarine and coastal areas [7].

Previous studies have made use of ocean color satellite images such as Sea-viewing Wide Field-of-view Sensor (SeaWiFS) $[43,2,13,25,4]$. Because of their low spatial resolution $(1 \mathrm{~km})$ these studies had limited ability to represent detailed analysis of changes in coastal areas. Thus satellites by relatively high spatial resolutions such as Landsat (30 $\mathrm{m})$ and SPOT (10 m), have also been used for coastal studies $[10,46,11,33)$. Although landobserving satellites have high spatial resolution images, their relatively poor temporal resolution is problematic for assessing dynamics of SSC on coastal areas [42]. The Moderate-Resolution Imaging Spectroradiometer (MODIS) with near 1-day temporal resolution that its first two bands is in $250 \mathrm{~m}$ spatial resolution, in visible and near-infrared portion of the electromagnetic spectrum making it possible to effectively analyze coastal SSC dynamics [33, 22, 5, 6, 2, 18, 47].

Mobasheri [28] observed an exponential relationship $\left(\mathrm{R}^{2}=0.49\right)$ between reflectance at MODIS band 4 and SSC in the BE. The range of SSCs was between 30 and $500 \mathrm{mg}$ $\mathrm{L}^{-1}$. He concluded atmospheric aerosols and low spatial resolution $(500 \mathrm{~m})$ causes for the poorness of the correlation coefficient. He also found that high values of SSC produce some difficulties in the deployment of the method [27]. To solve this problem some researchers have used Artificial Neural Network (ANN) as a more advanced modeling technique $[3,41]$. Studies showed that by an ANN with one hidden layer any function, no matter how complex, can be simulated [1].

In this study an ANN model was used to simulate the relationship between in situ measured SSC with a wide range from 116 to $786 \mathrm{mg} \mathrm{L}^{-1}$ and extracted reflectance from MODIS surface reflectance product (MOD09GQ), which has moderate spatial resolution and is atmospherically corrected to cover the weaknesses of previous study in atmospheric aerosols and low spatial resolution effects. As a contrast, regression analysis was performed using the same dataset, and the differences between these two methods were analyzed. Finally, by applying the model to MODIS images during 2003 to 2011 and consider the water depth (tide condition), spatial and temporal dynamics of SSC in $\mathrm{BE}$ was presented. The results could be used as a basis to adoption a cost effective water quality analysis strategy in the $\mathrm{BE}$ and other coastal areas.

\section{Materials and Methods}

\subsection{Study Area}

The Bahmanshir River (BR) that branches from the Karun River is located between $30^{\circ}-30^{\circ} 25^{\prime \prime} \mathrm{N}, 48^{\circ} 13^{\prime \prime}-48^{\circ} 43^{\prime \prime} \mathrm{E}$ at the southwest of Iran. Total length of BR is $80 \mathrm{~km}$ and it's wide in vicinity of the mouth is $600 \mathrm{~m}$. It depletion into the Persian Gulf and has the annual average discharge about $35 \mathrm{~m}^{3} \mathrm{~s}^{-1}$. It is a vital water resource for Khorramshahr and Abadan that are dense cities [36]. In this study, SSC dynamics were investigated in a square section of the $\mathrm{BE}$ with about $156 \mathrm{~km}^{2}$ (Figure 1). The high SSC in the BE is mainly due to input sediments from the BR and resuspened sediments due to the seasonal winds and daily tidal movements of water in the Persian Gulf. The dominant tidal component at the $\mathrm{BE}$ is the semi-diurnal M2 tide with an average tide range about $2.7 \mathrm{~m}$, and the historic peak value about $3 \mathrm{~m}$. The tidal influences may be observed as far as Ahvaz city in $120 \mathrm{~km}$ upstream of BE usually in summer (During dry season) when the Karun river discharge is very low. However, in normal condition the tidal influence can reach to about $48 \mathrm{~km}$ upstream of BE [36].

\subsection{In Situ Measurements}

In situ data should be collected when the satellites overpass, to quantify the relationship between satellite data and water quality, or calibrate algorithms to each specific site

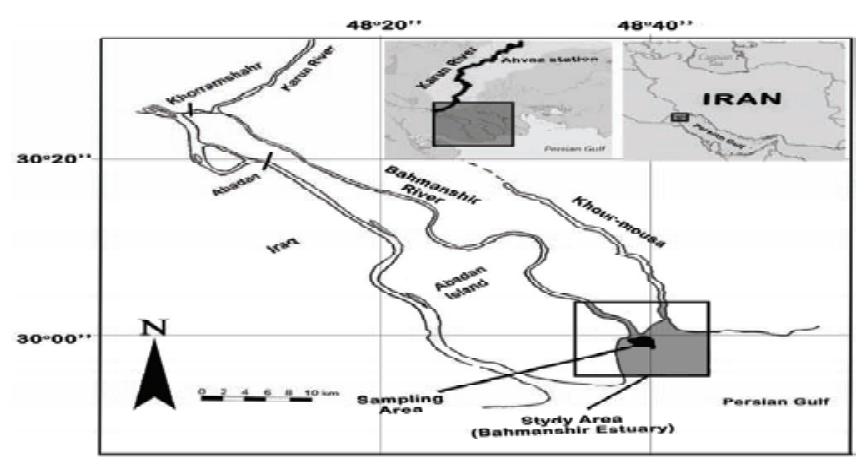

Figure 1. Location map of the Bahmanshir Estuary, span of study area and sampling area. 
Table 1. Statistics of data for SSC $\left(\mathrm{mg} \mathrm{L}^{-1}\right)$ model calibration and validation

\begin{tabular}{lccccc}
\hline $\begin{array}{l}\text { Campaign } \\
\text { number }\end{array}$ & $\begin{array}{l}\text { Sample } \\
\text { point } \\
\text { number }\end{array}$ & Max & Min & Mean & $\begin{array}{l}\text { Standard } \\
\text { deviation }\end{array}$ \\
\hline 1 & 6 & 514 & 346 & 418.1 & 59.1 \\
2 & 6 & 370 & 116 & 264.6 & 93.9 \\
3 & 6 & 644 & 444 & 537.1 & 81.1 \\
4 & 6 & 786 & 420 & 589.3 & 137.6 \\
5 & 5 & 536 & 384 & 462 & 65.5 \\
Total & 29 & 786 & 116 & 454 & 144 \\
\hline
\end{tabular}

$[37,20]$. The field sampling, was carried from various locations during five field campaigns between April 25 and June 11 of 2003 in the vicinity of the BE. It included latitude and longitude of the sampling point (using a GPS set), atmospheric visibility (for quality assessment of the images) and water sample for SSC measurement. Six or five SSC samples were collected for each campaign. The SSC range was from 116 to $786 \mathrm{mg} \mathrm{L}^{-1}$ that presented a large range of SSC. Water sampling was done by collecting surface water (200 to $1000 \mathrm{~mL}$ ) at depth, $0.1 \mathrm{~m}$ below the surface within range of \pm 30 minutes of a MODIS Terra overpass. It was conducted by the boat with a minimum distance of 500 meters apart. Total number of SSC samples were collected for a total of 29 data spread over the BE (shown in Figure 1). The samples were filtered under positive pressure, dried and then the volumes of the filtrates were measured with a graduated cylinder to measure in situ SSCs. Table 1 shows summary statistics of measured SSCs at each campaign.

\subsection{Satellite Image Data}

The MODIS sensor provides near-daily observation images in 36 spectral channels. First two of them are available at full spatial resolution $(250 \mathrm{~m})$. Band 1 is in the visible spectral domain $(620-670 \mathrm{~nm})$ and band 2 is in the nearinfrared (841-876 nm). The processing of MODIS original images requires at least three successive steps: (1) geolocating (2) atmospheric correction (3) conversion into percent surface reflectance. The second step is problematic, because there is no valid atmospheric correction algorithm for highly turbid waters currently [12]. A solution used in this study is surface reflectance atmospherically corrected products, MOD09GQ that has been used in other studies $[12,29,41]$.

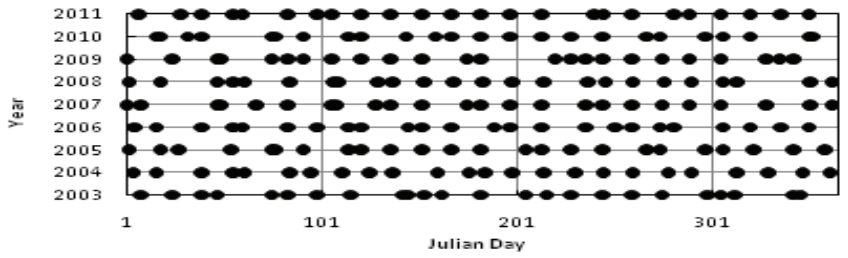

Figure 2. Date of MODIS images that were acquired for modeling and time series according to their julian day.

MOD09GQ is a daily MODIS surface reflectance product that gridded in level-2G. After a uniform quality assurance process, it is being to dataset in the sinusoidal projection and provides an estimate of the reflectance at sea level without atmospheric absorption and scattering. It is also corrected for adjacent effect and thin cirrus clouds for every pixel that identified as being cloud free using $6 \mathrm{~S}$ model on bands 1 and $2[40,39,49]$. It is not corrected for sun glint reflection at the air-water interface and although not sufficiently accurate to open ocean uses, but it is still appropriate for highly reflective estuarine waters. It has been reported that between 70 to $90 \%$ of the reflectance signal in the near infrared and about $80 \%$ in the red wavelength is due to turbid estuarine water [29]. This product is available without any charge from several data archive and distribution centers. Specific data can be selected for a given time period and geographic region using a web based query.

MODIS data are stored as data granules (5 min time of data collection). We needed 2 granules to cover the whole of it because geographic of BE. In addition, such as [45], we wanted to have 2 images per month ranging from 2003 January to 2011 December to create satellite image time series. Finally, a dataset of 442 images was downloaded from Reverb gateway [50] for days corresponding to field measurements and 232 days of time-series. Figure 2 shows the date of MODIS MOD09GQ products that were downloaded for modeling and generate time series according to their Julian day.

All images were processed by MODIS Reprojection Tool (MRT) including: mosaicing 2 granules of each day, subset study area, reprojection based on the geographic coordinate system. Then, due to the limited number of measured samples, data match ups were performed by manually navigating to sample locations and recording the MODIS band 1 and 2 reflectance values of the corresponding pixels by ESRI's ArcGIS version 10. Matlab version 7.8.0 was used to further processes and analysis of time series. 


\subsection{Other Environmental Data}

For considering tidal condition in SSC maps, water depth data of $\mathrm{BE}$ were downloaded for all days of time-series at acquisition time of images from the hydrographic department of the National Cartographic Center (NCC) of Iran using a web- based query [51].

Annual average discharge data of Karun River that BR branches from it were obtained from the Iran Water Resources Management Company. The discharge (Q) of Karun River measures every day by a river gauge located at the Ahvaz station (Figure 1) that is the nearest hydrometric station to BR.

\subsection{Artificial Neural Network Algorithm}

An ANN attempts to mimic, human mental and neural structures and functions, in a very simplified way [16]. The development of an ANN model consists of four steps: (1) selection of input and target (output) variables; (2) selection of model structure; (3) estimation of model parameters (training); and (4) validation of the model. In this study, inputs were the values of bands 1 and 2 of MODIS MOD09GQ surface reflectance product and target was SSC. In terms of structure, the ANN used in this study had three layers: an input layer, to present data to the network; an output layer, to produce an estimated response to the given input; and one hidden layer as it is proven to be sufficient in modeling any complex problem [1]. Figure 3 shows the basic structure of ANN used in this study, neurons in the input and hidden layers are shown by $B_{i}$ and $n_{i}$ respectively and the SCC neuron in output layer is the target.

The number of neurons of input layer was 2, that was equal to the number of used spectral channels of MODIS images and the output layer had only 1 neuron corresponding to the one target parameter (SSC). A complex problem may not resolve by using too few hidden layer neurons, while, over fitting accrues by using too many, and the network looses the capacity to generalize [23]. By the trial and error procedure that initially started with two hidden neurons, and increasing it to 10, 7 neurons of hidden layer were found to be sufficient for satisfactory modeling of SSC without over fitting. The ANN was a popular feed-forward type [9], and employed a back-propagation method for correcting the error. Each neuron of hidden layer was connected to all neurons in both of input and output layers with an associated weight and had one bias. Training of an $\mathrm{ANN}$ is to find the appropriate biases and weights in the interconnections that are the main modeling concept [44]. This is done as follows: The function that the output from neuron $i$ in a layer (receiving layer in a feed-forward manner) calculates is:

$$
\text { net }_{i}=f\left(\sum_{i=1}^{n} x_{i} w_{i j}+b_{i}\right)
$$

where $n$ is number of neurons in preceding layer, $f$ is activation function of layer, which are usually continuous and bounded, $x_{i}$ is input signal that transferred from preceding layer to the neurons in the receiving layer, $w_{i j}$ is the weight between neuron $j$ of preceding layer and the neuron $i$ of receiving layer, $b_{i}$ is the bias associated with neuron $i$ of receiving layer and net $t_{i}$ is the output from neuron $i$ in a receiving layer. The receiving neuron sums the weighted signals from all neurons in the preceding layer; this sum is then added to a bias and undergoes the activation function. The most commonly employed activation function that was used in this study was the "tansig function", which is defined:

$$
f=\frac{2}{1+e^{-2 s}}-1
$$

It is for any variable such as " $s$ ". The cross validation was used to assess the performance of ANN model [21]. The total dataset was divided into two groups: $23(80 \%)$ training and $6(20 \%)$ validation data subsets. The network output was compared with the true output of training data subset, when the signal reached the output layer [23]. The connection weights and biases were modified using the Levenberg-Marquardt procedure in the MATLAB software that used the methodology given by [34] and was back-propagated through output layer to previous layers. During the training process error was monitored by the several parameters, including coefficient of determination $\left(\mathrm{R}^{2}\right)$ and Root Mean Squared Error (RMSE). The training was conducted until the output error reaches a desired level. After training, network validation was done by comparing calculated and measured output of validation data subset by the $\mathrm{R}^{2}$ and RMSE.

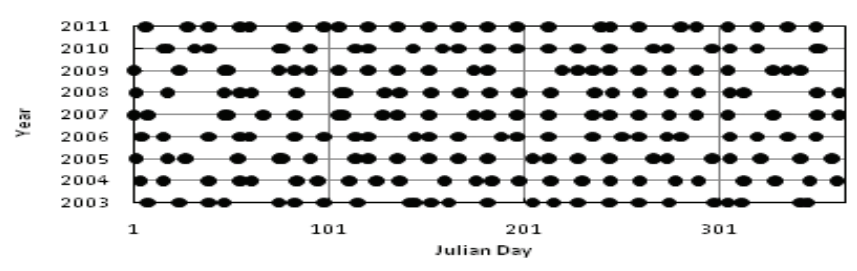

Figure 3. Artificial Neural Network model used in this study. 


\subsection{Regression Analysis}

Traditional methods of water quality parameters estimation often use a kind of regression analysis such as simple or multiple regressions for prediction problems, and discriminant analysis or logistic regression models for classification problems. Multiple and several types of simple regression analysis (linear, polynomial, exponential, logarithmic and power) with different band combinations were employed. Like ANN algorithm, SSC was dependent variable that estimated from reflectance values of MODIS MOD09GQ band 1 and 2 as independent variables. To indicate the significance of the regression analysis, cross validation was used including $\mathrm{R}^{2}$ and the RMSE such as the process used in ANN model. Regression modeling and validating was performed by using the same datasets that used in ANN training and validating, to compare with the ANN algorithm results.

\subsection{Mapping the Suspended Sediment Concentration}

Entire of images in time-series were simulated through the ANN by using Matlab software version 7.8.0. The outputs of the network were images, whose values of pixels were estimated SSCs of surface water that were named "SSC images". Then, annual SSC images of BE were retrieved by averaging the simulated images of the same years. Land pixels of images were removed by using a mean land-water mask within a specified timeframe (each year); however, deep sea water, most BR and adjacent coastal areas were still retained. It was in the following way: by considering water depth changes in the estuary because of tidal currents and river discharge dynamics, at the first step, several known pixels that geographically were land in all of the images, were selected as the landmark-pixels. Then, by averaging the band 2 reflectance of whole of participated images of time series in the desired year (each year), averaged pixels that have very near values (a reflectance difference threshold of $0.2 \%$ ) to the averaged land-mark-pixels value, were defined as land pixels. After this, binary "land-water images" were created by putting 0 and 1 values to pixels that were defined as land and water pixels respectively. In other words, a "land-water image" that obtained by the above processes is a mean "land-water image" for a specified timeframe (each year). Finally, by multiple "SSC-image" to their corresponding "land-water image" SSC map of a desired year was obtained. This procedure was done for all years.
More details about this technique were presented in this dissertation [19].

\section{Results and Discussion}

\subsection{SSC Retrieval Model Analysis}

Cross validation method was used to assess the performance of ANN model, after training. As the most common method regression analysis was used against the ANN. Table 2 shows the values of the $\mathrm{R}^{2}$ for the different methods of curve fitting with different band combinations for total data set (29 pairs). The best result of the regression analysis (that is marked with a star in the Table 2) was the exponential curve that fitted on reflectance of band 1 and in situ measured SSC. Because band 1 had the highest coloration with in situ SSC, cross validation performed on data pairs of this band reflectances and in situ SSCs pairs. Total data set divided into two groups like ANN model, $80 \%$ for modeling and $20 \%$ for validating. The exponential curve was fitted on modeling data subset that has the equation of the form:

$$
\left(R^{2}=0.63, \quad n=23\right) \quad S S C=22.92 B_{1}^{0.82}
$$

where $B_{1}$ is reflectance of band 1 in \%. Then calculated SSC from Eq. (3) and corresponding measured SSCs of validating data subset were compared. This also done on validation data subset of SSCs that calculated by ANN model. Cross validation results were compared for ANN and regression models in Table 3 by use of $\mathrm{R}^{2}$ and RMSE values for training (modeling) and validating data subsets. So the values of the $\mathrm{R}^{2}$ of training (modeling) data subset and RMSE of validation data subset improved 25 and $77 \%$ respectively when using the ANN model. The ANN model had good simulation performance (training: $\mathrm{R}^{2}=0.84 ; \mathrm{N}=23$; validation: RMSE of $59 \mathrm{mg} \mathrm{L}^{-1}, \mathrm{~N}=6$ ), therefore ANN model and MOD09GQ products have the capability to track dynamics of SSC in BE.

Figure 4 shows a graphical comparison between in situ measured and calculated SSCs of regression and ANN models for similar validation data subset that shows, ANN model was able to retrieve the SSC with higher accuracy than regression analysis. which was also observed in other studies $[35,41]$.

Figure 5 shows the relationship between in situ measurements of SSC and MODIS band 1 reflectance. The behavior of this band is complex in SSCs higher than 500 
Table 2. Regression analysis results for different curve fitting methods with different band combinations

\begin{tabular}{|c|c|c|c|c|c|}
\hline 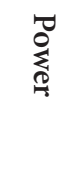 & 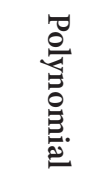 & 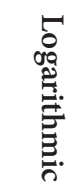 & 它. & 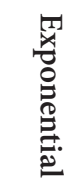 & Simple regressions \\
\hline $0.61^{*}$ & 0.41 & 0.36 & 0.31 & 0.50 & $\mathrm{~B}_{1}$ \\
\hline 0.26 & 0.24 & 0.16 & 0.09 & 0.16 & $\mathrm{~B}_{2}$ \\
\hline 0.55 & 0.39 & 0.33 & 0.26 & 0.42 & $\mathrm{~B}_{1}+\mathrm{B}_{2}$ \\
\hline 0.53 & 0.44 & 0.33 & 0.25 & 0.33 & $\mathrm{~B}_{1}-\mathrm{B}_{2}$ \\
\hline 0.47 & 0.37 & 0.29 & 0.13 & 0.22 & $\mathrm{~B}_{1} \mathrm{~B}_{2}$ \\
\hline 0.05 & 0.01 & 0.02 & 0.00 & 0.02 & $\mathrm{~B}_{1} / \mathrm{B}_{2}$ \\
\hline 0.46 & 0.33 & 0.28 & 0.36 & 0.54 & $\operatorname{Ln}\left(B_{1}\right) \operatorname{Ln}\left(B_{2}\right)$ \\
\hline 0.20 & 0.25 & 0.12 & 0.14 & 0.23 & $\operatorname{Ln}\left(B_{1}\right) / \operatorname{Ln}\left(B_{2}\right)$ \\
\hline 0.43 & 0.34 & 0.26 & 0.29 & 0.47 & $\operatorname{Ln}\left(B_{1} B_{2}\right)$ \\
\hline 0.07 & 0.01 & 0.05 & 0.02 & 0.05 & $\operatorname{Ln}\left(B_{1} / B_{2}\right)$ \\
\hline \multicolumn{5}{|c|}{$\begin{array}{l}\mathrm{SSC}=27.57 \mathrm{~B}_{1}-75.51 \mathrm{~B}_{2}+126.15 \\
\mathrm{R}^{2}=0.31\end{array}$} & Multiple regression \\
\hline
\end{tabular}

Table 3. ANN and regression models results

\begin{tabular}{|c|c|c|c|c|}
\hline \multicolumn{2}{|c|}{ Regression } & \multicolumn{2}{|c|}{ ANN } & \\
\hline Validating & Modeling & Validating & Training & \\
\hline 0.44 & 0.63 & 0.93 & 0.84 & $\mathrm{R} 2$ \\
\hline 261.84 & 231.67 & 59.65 & 55.76 & $\mathrm{RMSE}(\mathrm{mg} / \mathrm{l})$ \\
\hline 6 & 23 & 6 & 23 & $\mathrm{~N}^{*}$ \\
\hline${ }^{*} \mathrm{~N}$ is numb & $r$ of samples & & & \\
\hline
\end{tabular}

$\mathrm{mg} \mathrm{L}^{-1}$ and becomes from linear to non-linear at this point. In other word this spectral band is saturated. This has been also observed in other studies $[41,42]$ and can be a cause for poor performance of regression analyzes.

\subsection{Spatial Variation of SSC in BE}

Regions with high SSC in estuary are pressed toward the Estuary Mouth (EM) by rising water depth and are expanded by decline in water depth [27]. Water depth in BE continually changing because it is influenced simultaneous by river flow from upstream and tidal currents from downstream. Therefore water depth (tidal conditions) must

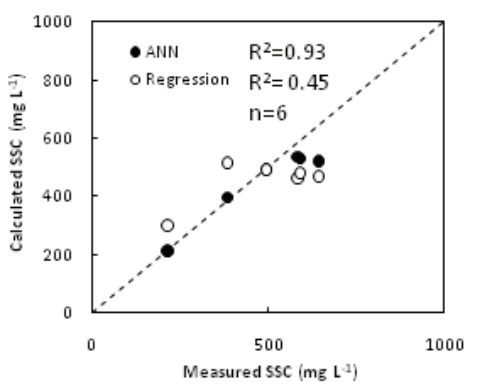

Figure 4. Comparison between in situ measurements and calculated values of validation data subsets for the ANN and regression models.

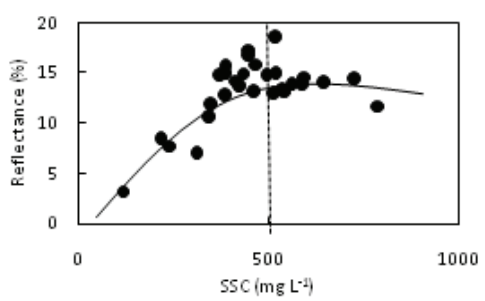

Figure 5. Changes of band 1 reflectance against SSC.

be considered in SSC maps. Figure 6 shows maps of annual average SSC in BE that retrieved by using ANN model. Average water depth is mentioned in each map. In this study because of approximately low changes of average water depth in different years of time series (standard deviation of annual water depth is $0.16 \mathrm{~m}$ ), effect of tidal condition was not considered in the temporal and spatial SSC variation assessment.

Highest SSC occurs at the EM in almost all maps and input currents from the BR and Khure Mousa on the left bank of the BR can be distinguished due to higher SSCs. For a more detailed assessment of the spatial changes of SSC, two paths along the BR canal (path A) and coastline (path B) that are shown in Figures 7 and 8 were selected. In the Figure 7 the EM has been chosen as the origin, from this point toward the upstream distance is negative and toward the sea is positive.

As can be seen in Figure 7, SSC decreases from upstream of BE to approximately $3.2 \mathrm{~km}$ before point EM (from 1060 to $660 \mathrm{mg} \mathrm{L}^{-1}$ ), and then increases toward the EM (from 660 to $\left.1040 \mathrm{mg} \mathrm{L}^{-1}\right)$, this point is labeled with the name of $(\mathrm{M})$, that shows an approximately $36 \%$ reduction of SSC in comparison with the point EM and upstream of BR. Suspended sediments that are deposited along the $\mathrm{BR}$ and $\mathrm{BE}$ are as results of upstream flow from $B R$ and tidal currents from 


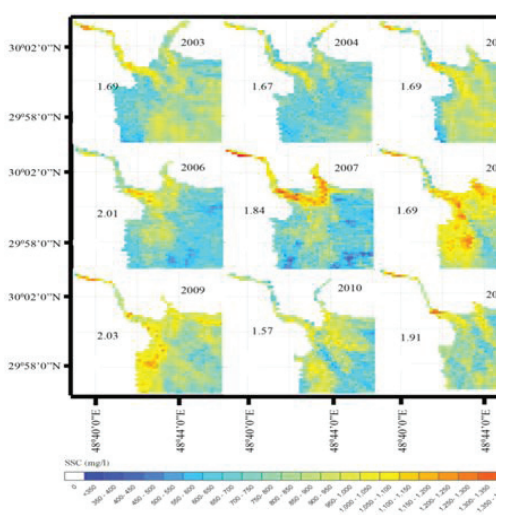

Figure 6. Annual maps of average SSC $\left(\mathrm{mg} \mathrm{L}^{-1}\right)$ in BE from 2003 to 2011.

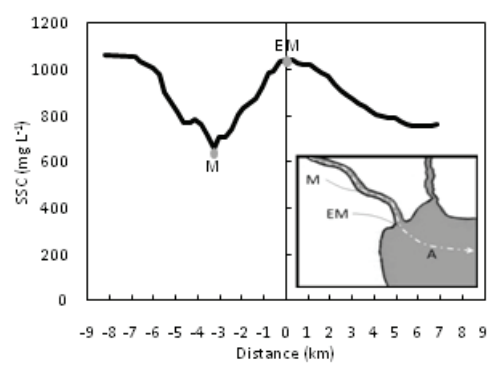

Figure 7. Spatial changes of average SSC $\left(\mathrm{mg} \mathrm{L}^{-1}\right)$ along the BR canal (path A).

BE. It seems we can conclude that, the point $\mathrm{M}$ is a boundary point, so that from this point toward the upstream along the BR SSC value is more influenced by BR flow, and in contrast, from this point toward the downstream SSC is more influenced by tidal currents from BE.

Changes of average SSC along the coast is presented in the Figure 8. EM is also origin and direction of movement from negative to positive has been specified. As can be seen, high SSCs occur in near the EM. Maximum SSCs in the right bank of $\mathrm{BR}$ is observed at distance $2.8 \mathrm{~km}$ from the point EM in the muddy shore of Abadan island and from $1.8 \mathrm{~km}$ in left bank at the Khoure Muosa.

\subsection{Temporal Variation of SSC in BE}

Karun River is the only supplier of BR, therefore, data of Karun River discharge at the Ahvaz station (nearest hydrometric station to BR) were used for assessing BR discharge changes. Figure 9 shows the annual variations of SSC and Karun River discharge. An inverse relation between SSC and discharge can be seen, this means that, reduction of discharge causes an increase in SSC. The highest SSC have occurred in 2008 coincided with a noticeable decrease in

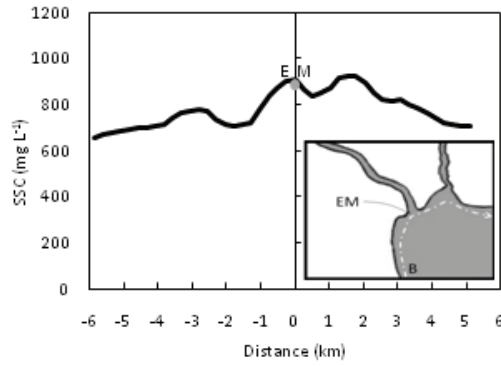

Figure 8. Spatial changes of average SSC $\left(\mathrm{mg} \mathrm{L}^{-1}\right)$ along the BE (path B).

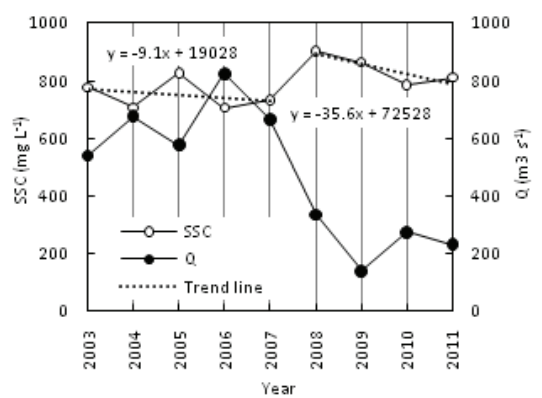

Figure 9. Annual variations of the SSC $\left(\mathrm{mg} \mathrm{L}^{-1}\right)$ from 2003 to 2011 .

discharge of the Karun River in this year. Two trend lines were traced on annual average SSC of the years 2003 to 2007 and 2008 to 2011. Trend line slope of years 2003-2007 is -9.1 and for 2008-2011 is -35.6 . Therefore, SSC changes before 2008 were less than subsequent years.

The average SSC for the years 2003 to 2007 and 2008 to 2011 were 750 and $840 \mathrm{mg} \mathrm{L}^{-1}$ respectively, that represents a $10 \%$ increase of average SSC for the years 2008 to 2011 in compared with the years 2003 to 2007. It can be concluded, the general trend of changes of SSC at BE during the years from 2003 to 2011 has been increasing.

\section{Conclusions}

The temporal and spatial variations of SSC in BE from 2003 to 2011 were investigated. A feed forward type of ANN with one hidden layer was used for retrieving SSC. Results demonstrated that the recorded reflectance of band 1 MODIS $250 \mathrm{~m}$ surface reflectance product has a good relationship with in situ SSC measurements $\left(\mathrm{R}^{2}=0.61\right)$. Regression analysis was used as the most common method, against ANN. $\mathrm{R}^{2}$ and RMSE improved, 25 and $77 \%$ respectively when using the ANN that shows, ANN model was able to model 
the SSC with higher accuracy than regression model. It was observed that, the relationship between MODIS band 1 reflectance (that had the highest correlation with SSC) and SSC was linear in SSC range $0-500 \mathrm{mg} \mathrm{L}^{-1}$ and nonlinear for higher SSCs. In other word this spectral band was saturated. This can be the cause of poor performance of regression analysis in compared to the ANN. By applying the validated ANN models on MODIS images, the annual maps of SSC in BE were obtained. Results showed, minimum SSC occurs at a point about $3.2 \mathrm{~km}$ before the EM. This point can be defined as the boundary of impact of upstream and downstream on the SSC in the BE. Identifying this point can help future researchers to investigate the status of suspended sediment in the upstream and downstream of BR individually. Highest SSCs occur at the EM point, at the muddy shore of Abadan island on the right bank of BR and the Khoure Mousa on the left bank with 2.8 and $1.8 \mathrm{~km}$ distance from the EM respectively. It was found that annual average SSC for 2008 to 2011 was $10 \%$ more than 2003 to 2007 and 2008 had the highest SSC coincided with a noticeable decrease in discharge of the Karun River in this year. MOD09GQ products and the ANN have the capability to track dynamics of SSC in BE as shown in this study. In this study, impact of average water depths on the SSC maps was not considered due to their relatively low changes in annual timeframes. It is suggested to consider the quantitative impact of water depth on SSC variations for a more accurate investigation in further works. The method presented in this study can be used in other coastal waters. Achieved algorithm has ability to store and apply to the images of each desired date and gives the possibility of SSC monitoring in less time and cost for environmental researchers and water quality managers.

\section{Acknowledgements}

The authors want to thank Dr. Mohammad Reza Mobasgeri, Mr. Seyed Hamid Mousavi and Mr. Amir Ashtari for providing the in situ data, and hydrographic department of the National Cartographic Center for providing useful tide information. Authors also thank the Reverb gateway (NASA) for providing MODIS satellite data.

\section{References}

1. Bsseale R, and Jackson T (1990). Neural computing: an introduction, Adam Hilger, Bristol.

2. Binding C E, Bowers D G et al. (2003). An algorithm for the retrieval of suspended sediment concentrations in the
Irish Sea from SeaWiFS ocean colour satellite imagery, International Journal of Remote Sensing, vol 24(19), 37913806.

3. Canziani G, Ferrati R et al. (2008). Artificial neural networks and remote sensing in the analysis of the highly variable pampean shallow lakes, Mathematical Biosciences and Engineering, vol 5(4), 691-711.

4. Chen C, Tang C et al. (2007). Remotely sensed assessment of water quality levels in the Pearl River Estuary, China, Marine Pollution Bulletin, vol 54(8), 1267-1272.

5. Chen S S, Huang W et al. (2009). Remote sensing assessment of sediment re-suspension during Hurricane Frances in Apalachicola Bay, USA, Remote Sensing of Environment, vol 113(12), 2670-2681.

6. Chen S, Huang W et al. (2011). An enhanced MODIS remote sensing model for detecting rainfall effects on sediment plume in the coastal waters of Apalachicola Bay, Marine Environmental Research, vol 72(5), 265-272.

7. Cracknell A P (1999). Remote sensing techniques in estuarine and coastal zone-an update, International Journal of Remote Sensing, vol 20(3), 485-496.

8. Curran P J, and Novo E M M (1988). The relationship between suspended sediment concentration and remotely sensed spectral radiance: a review, Journal of Coastal Research, vol $4(3), 351-368$.

9. Dawson D W, and Wilby R (1998). An artificial neural network approach to rainfall-runoff modeling, Hydrological Sciences Journal, vol 43(1), 47-65.

10. Dekker A G, Vos R J et al. (2001). Comparison of re-mote sensing data, model results and in situ data for total suspended matter (TSM) in the southern Frisian lakes, Science of the Total Environment, vol 268(1-3), 197-214.

11. Doxaran D, Froidefond J M et al. (2002). Spectral signature of highly turbid waters. Application with SPOT data to quantify suspended particulate matter concentrations, Remote Sensing of Environment, vol 81(1), 149-161.

12. Doxaran D J M, P Castaing et al. (2009). Dynamics of the turbidity maximum zone in a macrotidal estuary (the Gironde, France): Observations from field and MODIS satellite data, Estuarine Coastal and Shelf Science, vol 81(3), 321-332.

13. Figueras D, Karnieli A et al. (2004). Masking turbid water in the southeastern Mediterranean Sea utilizing the SeaWiFS $510 \mathrm{~nm}$ spectral band, International Journal of Remote Sensing, vol 25(19), 4051-4059.

14. Gao J, and O'Leary S M (1997). Estimation of suspended solids from aerial photographs in a GIS, International Journal of Remote Sensing, vol 18(10), 2073-3086.

15. Gordon H R, and Morel A Y (1983). Remote assessment of ocean color for interpretation of satellite visible imagery: a review, Lecture Notes on Coastal and Estuarine Studies, vol 4,114 . 
16. Hsieh C (1993). Some potential applications of artificial neural networks in financial management, Journal of Systems Management, vol 44(4), 12-15.

17. $\mathrm{Hu} \mathrm{C}$, Chen $\mathrm{Z}$ et al. (2004). Assessment of estuarine waterquality indicator using MODIS medium-resolution bands: initial results from Tampa bay, FL, Remote Sensing of Environment, vol 93(3), 423-441.

18. Huang W, Mukherjee D et al. (2011). Assessment of Hurricane Ivan impact on chlorophyll-a in Pensacola Bay by MODIS $250 \mathrm{~m}$ remote sensing, Marine Pollution Bulletin, vol 62(3), $490-498$

19. Kazemzadeh M B (2013). Assessment of temporal and spatial changes of suspended sediment concentration in Bahmanshir tidal estuary using remote sensing technique, Tarbiat Modares University (TMU), 163.

20. Keiner L E, and Yan X H (1998). A neural network model for estimating sea surface chlorophyll and sediments from Thematic Mapper Imagery, Remote Sens Environ, vol 66, $153-165$.

21. Kwok T Y, and Yeung D Y (1995). Efficient cross-validation for feed forward neural networks, IEEE International Conference on Neural Networks Proceedings, 1995, vol 5, 2789-2794.

22. Martinez J M, Guyot J L et al. (2009). Increase in suspended sediment discharge of the amazone River assessed by monitoring network and satellite data, Catena, vol 79, 257-264.

23. Masters T (1993). Practical Neural Network Recipes in C++, Morgan Kaufmann, San Francisco, 344-346.

24. Mayer L M, Keil R G et al. (1998). Importance of suspended particulates in riverine delivery of bioavailable nitrogen to coastal zones, Global Biogeochemical Cycles, vol 12(4), 573-579.

25. Melin F, Zibordi G et al. (2003). Assessment of SeaWiFS Atmospheric and Marine Products for the Northern Adriatic Sea, IEEE Transactions on geoscience and remote sensing, vol 41(3), 548-558.

26. Min J E, Ryu J H et al. (2012). Monitoring of suspended sediment variation using Landsat and MODIS in the Saemangeum coastal area of Korea, Marine Pollution Bulletin, vol 64(2), 382-390.

27. Mobasheri M R (2008). Assessment of suspended sediment concentration in surface waters, using modis Images, American Journal of Applied Sciences, vol 5(7), 798-804.

28. Mobasheri M R (2010). Remote sensing of tidal situation by monitoring change in suspended sediment concentration, Surface Waters. Journal of the Persian Gulf (Marine Science), vol 1(1), 37-44.

29. Moreno-Madriñán M J, Al-Hamdan M Z et al. (2010). Using the surface reflectance MODIS Terra product to estimate turbidity in Tampa Bay, Florida, Remote Sensing, vol 2(12), 2713-2728.
30. Olsen C R, Cutshall N H et al. (1982). Pollutant-particle associations and dynamics in coastal marine environments: A review, Marine Chemistry, vol 11(6), 501-533.

31. Panda S S, Garg V et al. (2004). Artificial neural network application in lake water quality estimation using satellite imagery, Journal of Environmental Informatics, vol 4(2), 65-74.

32. Parsa J, Etemad-Shahidi A et al. (2007). Evaluation of computer and empirical models for prediction of salinity intrusion in the Bahmanshir estuary, Journal of Coastal Research, Special Issue 50, 658-662.

33. Pavelsky T M, and Smith L C (2009). Remote sensing of suspended sediment concentration, flow velocity, and lake recharge in the peace-Atabasca Delta, Canada, Water Resources Research, vol 45, 1-16.

34. Press W H, Teukolsky S A et al. (1992). Numerical Recipes in C: The Art of Scientific Computing, $2^{\text {nd }}$ Edn., Cambridge University Press.

35. Sudheer K P, Chaubey I et al. (2006). Lake water quality assessment from Landsat thematic mapper data using neural network: an approach to optimal band combination selection, Journal of the American Water Resources Association, vol 42(6), 1683-1695.

36. Sweco-Mahab (1976). Abadan Island and Khorramshahr water supply and irrigation project hydraulic condition and salt water mathematical model studies, Khuzestan Water and Power Organization, Technical Report, Iran, 184.

37. Tassan S (1994). Local algorithms using SeaWiFS data for the retrieval of phytoplankton, pigments, suspended sediment, and yellow substance in coastal waters, Applied Optics, vol 33(12), 2369-2378.

38. Torres J L, and Morelock J (2002). Effect of terrigenous sediment Influx on coral cover and linear extension rates of three Caribbean massive coral species, Caribbean Journal of Science, vol 38(3-4), 222-229.

39. Vermote E F, El Saleous et al. (2002). Atmospheric correction of MODIS data in the visible to middle infrared: first results, Remote Sensing of Environment, vol 83(1-2), 97-111.

40. Vermote E F, and Vermeulen A (1999). Atmospheric correction algorithm: spectral reflectances (MOD09), Algorithm Technical Background Document (ATBD) version 4.0.

41. Wang F, Zhou B et al. (2009). Application of neural network and MODIS $250 \mathrm{~m}$ imagery for estimating suspended sediments concentration in Hangzhou Bay, China, Environment Geology, vol 56(6), 1093-1101.

42. Wang J J, and Lu X X (2010). Estimation of suspended sediment concentrations Terra MODIS: an example from the Lower Yangtze River, China. Science of the Total Environment, vol 408(5), 1131-1138.

43. Warrick J A, Merters L A K et al. (2004). Estimating suspended sediment concentrations in turbid coastal waters of the Santa Barbara Channel with SeaWiFS, International Journal of Remote Sensing, vol 25, 1995-2002. 
44. White H (1989). Learning in Artificial Neural Networks: A Statistical Perspective. Neural Computation, vol 1, 425-464.

45. Zhang Y, Lin S et al. (2010). Time-series MODIS imagebased retrieval and distribution analysis of total suspended matter concentrations in Lake Taihu (China), Int. J. Environ. Res. Public Health, 7(9), 3545-3560.

46. Zhao D, Cai Y et al. (2011). Estimation of water clarity in Taihu Lake and surrounding rivers using Landsat imagery, Advances in Water Resources, vol 34(2), 165-173.
47. Zhou D (2012). Retrieval lo suspended sediment concentration in near-shor coastal waters using MODIS data, Msc thesis, Massey University, Palmerston North New Zelan, 70.

48. Available from: http://en.wikipedia.org/wiki/Khorramshahr\#cite_note-2;

49. Available from: http://6s.ltdri.org

50. Available from: http://reverb.echo.nasa.gov

51. Available from: http://www.iranhydrography.org/services.asp 